\title{
Los vacíos de la Ley 1709 de 2014 para el otorgamiento de la libertad condicional en Colombia
}

As lacunas da Lei 1.709 de 2014 para a concessão de liberdade condicional na Colômbia

Autores: Luz Mireya Mendieta Pineda, Wilmar Niño Hernández y Blanca M. Molina Carrión

DOl: https://doi.org/10.25058/1794600X.1798 


\title{
LOS VACÍOS DE LA LEY 1709 DE 2014 PARA EL OTORGAMIENTO DE LA LIBERTAD CONDICIONAL EN COLOMBIA*
}

\author{
As lacunas da Lei 1.709 de 2014 para a concessão de liberdade \\ condicional na Colômbia
}

\author{
Gaps in Law 1709 of 2014 for the granting of parole in \\ Colombia
}

\author{
Luz Mireya Mendieta Pineda ${ }^{a}$ \\ luz.mendieta@uptc.edu.co \\ Wilmar Niño Hernández \\ wilmar.nino@uptc.edu.co \\ Blanca M. Molina Carrión ${ }^{c}$ \\ molinacarrion22@gmail.com
}

Fecha de recepción: 04 de mayo de 2020 Fecha de revisión: 06 de junio de 2020

Fecha de aceptación: 18 de junio de 2020

DOI: http://doi.org/10.25058/1794600X.1798

Para citar esta colaboración especial:

Mendieta Pineda, L.; Niño Hernández, W. y Molina Carrión, B. (2020). Los vacíos de la Ley 1709 de 2014 para el otorgamiento de la libertad condicional en

Colombia. Revista Misión Jurídica, 13, (19). 270-288.

\footnotetext{
*Artículo de Investigación desarrollado en cooperación entre el "Grupo de investigación Derechos humanos y Medio ambiente", Reconocido y Clasificado en MINCIENCIAS 2018 Universidad Pedagógica y Tecnológica de Colombia UPTC; "Grupo de Investigación Red Internacional de Política Criminal Sistémica Extrema Ratio UN" Reconocido y Clasificado en A1 MINCIENCIAS 2018 Universidad Nacional de Colombia y la Maestría en Derecho Procesal Penal, Universidad Autónoma de Santo Domingo UASD.

a. Docente investigadora, asociada de la Facultad de Derecho y Ciencias Sociales de la Universidad Pedagógica y Tecnológica de Colombia, abogada, especialista en instituciones jurídico-políticas. Magister en Derecho Procesal de la Universidad Libre. Doctora en Derecho Penitenciario de la Universidad Libre. Código ORCID: 0000-0003-0371-5012. Email:

b. Abogado y Joven Investigador de la Universidad Pedagógica y Tecnológica de Colombia, grupo de investigación Derechos Humanos y Medio Ambiente. Código ORCID: 0000-0002-0580-3545.

c. Doctora en Derecho Universidad Iberoamericana UNIBE, República Dominicana, especialidad en Derechos Humanos y Derecho Internacional Humanitario, Instituto Superior para la Defensa Insude, (en curso); Magíster en Derecho Procesal Penal, Universidad Autónoma de Santo Domingo UASD (en curso). Investigadora en Estancia 2019 en el "Grupo de Investigación Red Internacional de Política Criminal Sistémica Extrema Ratio UN" Reconocido y Clasificado en A1 MINCIENCIAS 2018 Universidad Nacional de Colombia. Código ORCID: 0000-0002-5290-5974.
} 


\section{RESUMEN}

Este artículo presenta una reflexión a la comunidad académica, resultado de un estudio sobre la figura de la libertad condicional en Colombia, consagrada en la normatividad actual, como un subrogado penal de la pena de prisión, buscando responder cuál ha sido el impacto de la libertad condicional posterior a la Ley 1709 de 2014. Es una investigación socio-jurídica, que usa una metodología científica llamada desk table research, que tiene en su estudio la verificación de varias técnicas metodológicas, y en las que se usaron: la revisión de jurisprudencia, análisis doctrinal latinoamericano y recolección de datos genéricos a partir de diversos informes del INPEC. Así mismo se hizo un análisis crítico-jurídico de la Ley 1709 de 2014, respecto a la realidad social, que mostró las lagunas y vacíos existentes en su aplicación normativa.

Como un primer avistamiento y conforme a los resultados obtenidos de los informes emitidos por el INPEC, se puede concluir que a la libertad condicional acceden muy pocos $\mathrm{y}$, por lo tanto, un gran número de sentenciados debe cumplir la totalidad de la pena.

\section{PALABRAS CLAVE}

Pena; libertad; subrogado penal; sistema penitenciario y carcelario.

\begin{abstract}
This article presents a consideration for the academic community, it is the result of a study on the parole figure in Colombia, established in current regulations, like criminal subrogation of prison sentence, searching to answer what has been the impact in the granting of parole after Law 1709 of 2014. This is a socio-legal investigation that uses a scientific metodology called desk table research which includes in its study the verification of various metodological techniques and in those were used: jurisprudence review, Latin American doctrinal analysis and collection of generic data from various INPEC reports. Moreover, a critical-legal analysis of Law 1709 of 2014 was done regarding social reality, this showed the existing gaps and voids in its aplicable legislations.
\end{abstract}

As a first sighting and according to the results obtained from the reports issued by INPEC, it can be concluded that very few people obtain parole, thus a great number of those condemned must comply with their full sentence.

\section{KEY WORDS}

Sentence, criminal subrogation, penitentiary and prison system.

\section{RESUMO}

Este artigo apresenta uma reflexão para a comunidade acadêmica, resultado de um estudo sobre a figura da liberdade condicional na Colômbia, consagrada na regulamentação em vigor, como substituto criminal da pena de prisão, buscando responder qual foi o impacto sobre a concessão de liberdade condicional após a Lei 1.709 de 2014. É uma investigação sóciojurídica, que utiliza uma metodologia científica denominada desk table research, que tem em seu estudo a verificação de diversas técnicas metodológicas, e nas quais foram utilizadas: revisão de jurisprudência, análise doutrinária latino-americana e coleta de dados genéricos de diversos relatórios do INPEC. Da mesma forma, foi feita uma análise crítico-jurídica da Lei 1.709 de 2014, no que se refere à realidade social, que evidenciou as lacunas na sua aplicação regulatória.

À primeira vista e de acordo com os resultados obtidos nos laudos do INPEC, pode-se concluir que pouquíssimos acessam a liberdade condicional e, portanto, grande número dos condenados deve cumprir a pena integral.

\section{PALAVRAS-CHAVE}

Penalidade; liberdade; substituto criminoso; sistema penitenciário e prisional.

\section{INTRODUCCIÓN}

La libertad condicional es un subrogado penal que fue consagrado en la Ley 95 de 1936 (TITULO III, Condena y libertad condicionales y perdón judicial, desde artículo 81, hasta el artículo 92) y que, aun hoy, permanece con algunas modificaciones. Con este subrogado se busca que el sentenciado que ha cumplido los requisitos exigidos salga antes de cumplir la totalidad de la pena y se reintegre a la sociedad. 
Entre los años 2009 y 2013 se registraron altas tasas de hacinamiento en el sistema penitenciario y carcelario, mientras paralelamente aumentó la violación de derechos fundamentales del privado de la libertad, lo que llevó a que la Corte Constitucional en el 2013, por segunda vez, declarara el estado de cosas inconstitucional del sistema penitenciario y carcelario de Colombia (Corte Constitucional, T-388/13, 2013).

En enero de 2014 se expide la Ley 1709 de 2014 que modifica algunos artículos, entre ellos, el de la libertad condicional y amplia el aspecto objetivo y subjetivo con el fin que los privados de la libertad accedieran, aparentemente, de manera más fácil a este subrogado. En el desarrollo de la investigación y a través de los informes registrados del INPEC se buscó establecer si el cambio realizado a esta figura dio o no resultado.

Para poder comprender la figura, se hizo un breve acercamiento al concepto, tomando como fuente la interpretación del derecho, los precedentes judiciales y la norma, para luego hacer un análisis a la exclusión de la libertad condicional para algunas conductas punibles entre los años 2000 y 2014. Luego se analiza la modificación que sufrió la libertad condicional con la Ley 1709 de 2014, su otorgamiento y revocatoria. A seguir la investigación abordará la falta de legitimidad de las instituciones, la ineficacia de la norma y el gran problema que surge de los cambios normativos y sus vacíos interpretativos. Por último, y de acuerdo a los informes que registra el INPEC, se verifica el impacto real de la figura después de su modificación.

\section{ANTECEDENTES NORMATIVOS Y ORIGEN EN COLOMBIA}

\subsection{Aclaración terminológica y origen normativo de la libertad condicional}

El significado gramatical de la palabra subrogado, que se utiliza jurídicamente en materia penal, es: "persona o cosa puesta en lugar de otra para sucederla en sus derechos o para obrar por ella" (Larousse Gran Diccionario, 2020). El art. 67 de la Ley 19 de 1980, que fue adicionado por la Ley 83 de 1915, introdujo el término "subrogado" hablando por primera vez en la legislación penal de suspender la ejecución de la pena "si el procesado no hubiere incurrido antes en otra condenación y comprobare plenamente haber observado siempre buena conducta". Esto es, introduciéndose la figura que hoy conocemos como suspensión de la ejecución de la pena consagrada en el art. 63 del Código Penal. Años más tarde en el art. 85 y siguientes de la Ley 95 de 1936, se introduce la figura de la libertad condicional. En la actual legislación penal no se habla de subrogado penal, por el contrario, lo toma como un mecanismo sustitutivo de la pena privativa de la libertad, pero ello no es indicativo de que haya desaparecido dicho nombre, la Corte y su jurisprudencia, precedente típico del common law, hacen mención referente en la toma en varias decisiones.

Los subrogados penales son medidas sustitutivas de la pena de prisión y arresto, que se conceden a los individuos que han sido condenados a estas penas, siempre y cuando cumplan los requisitos establecidos por el legislador. De acuerdo con la legislación, los subrogados penales son: 1) la condena de ejecución condicional y 2) la libertad condicional (Corte Constitucional, C-679/98. 1998)

Antes de profundizar en el tema propuesto, es pertinente dar una luz a lo que se puede considerar uno de los orígenes de la idea de la libertad condicional, que es considerar al derecho y su omnipresencia como una manifestación de muchas otras instituciones sociales que es aceptable a la hora de contribuir a superar dificultades que tienen relación con la vida humana. Esas dificultades se ven enmarcadas en la vulnerabilidad de los seres humanos que se encuentran cumpliendo una pena, la incipiente falta de simpatía de las instituciones respecto a las necesidades de los reclusos o una limitada falta de racionalidad, que puede conducir a múltiples agresiones, hablando ya del tema que nos acoge. En esta circunstancia el derecho se puede presentar como una maquinaria funcional, utilizada por las mujeres y los hombres, a la hora de evitar o resolver dificultades sociales complejas o no.

No hemos dicho mucho de lo que ya se comprende, pero si hacemos una introspección y llegamos hasta la fuente misma de la relación hombre-derecho, encontraríamos a primera vista la existencia de dos elementos de cómo el derecho, puede persuadir a los seres humanos, a los que Nino (2003) denominaba como 
Autoridad y Coacción. Como en esa primera medida de Autoridad, se han creado instituciones que indiquen una conducta genérica, este camino en un sentido más amplio seria lo que se desea de un individuo en sociedad, que bien consideramos carecen de muchas circunstancias o problemas fenomenológicos. Pensemos ahora en una constitución que, en su articulado, prohíba rotundamente cualquier trato inhumano sobre el ser humano, violaciones, asesinatos torturas, en fin, cualquier trato degradante de la dignidad; esto ya dice mucho de los conflictos sociales que acarrea dicha sociedad, y de cómo pudieron llegar a formalizar una conducta genérica en un documento. Aunque no se critica los documentos robustos donde se formalizaron las conductas y prohibiciones, si se critica la violación incesante de lo plasmado.

Ahora bien, estas instituciones también participan o tienen un papel preponderante en resolver casos que están alejados de la conducta genérica esperada. Por ejemplo, una persona que, sin importar el conocimiento normativo y el articulado en la Constitución, o más complejo, sin mediar la racionalidad de sus conductas, lesionó en su integridad a otra persona, causándole un perjuicio corporal; esta persona que causó el perjuicio, según las reglas de las instituciones, tendría que cumplir un castigo o una pena según la gravedad de las afectaciones. Dichas reglas de estas instituciones, tienen como base inicial el disuadir a las personas a realizar determinadas conductas (asesinar, robar, entre otras) buscando en sí mismas evitar un deterioro de la sociedad (Ávila, 2017); sin embargo, también estas instituciones, después de ser superado esa etapa inicial de persuasión, pueden promover la ejecución de ciertos actos, que en nuestro caso sería la privación de la libertad y la suspensión de otros derechos (locomoción).

Se esperaría de estas instituciones que pudieran soportar medidas o ciertos actos, que ayuden a quien causó el deterioro de la sociedad a una resocialización e inclusión dentro de su entorno social, esto sería la libertad condicional. Esta conclusión deriva en poder entender que las instituciones con sus reglas y conductas genéricas, podrían atraer una dualidad en la aprobación de las normas mencionadas, es decir, frente a la aceptación y posterior cumplimiento de la regla, existiría al menos un beneficio, en el caso mencionado podría ser una reducción de la pena o acudir a la libertad condicional. Esto sería una conducta deseable, de parte del victimario, que así mismo tendría unas conductas más específicas para incurrir en tal beneficio, lo que explicaremos más adelante. Sin embargo, ¿qué pasa si esta persona, no cumple a cabalidad con la conducta, si no satisface lo esperado, o mejor, no existe obediencia de la directriz?, pues como resultado ya no existiría dicho beneficio, como este llegó -o le fue otorgado-, de la misma forma podría arrebatarsele, generando así una coacción, la cual sería el cumplimiento de la pena completa.

\subsection{Concepto}

Aproximándonos a una idea más clara, la Corte Constitucional, en su precedente, ha manifestado su postura frente a la libertad condicional, clasificándola como un subrogado de las penas. Esta corporación ha dicho que:

(...) los subrogados penales son medidas sustitutivas de las penas de prisión y arresto, siempre y cuando se cumplan los requisitos establecidos por el legislador. De acuerdo con la legislación, los subrogados penales son: 1) la suspensión condicional de la ejecución de la pena, 2) la libertad condicional, 3) reclusión hospitalaria (Corte Constitucional, Sentencias C-762/02. 2002, C-806/02. 2002, C-757/14, 2014, T-019/17. 2017, T-640/17. 2017).

Zafaroni ha manifestado que la libertad condicional trata de "una suspensión parcial de la privación del encierro que tiene lugar durante un periodo de prueba que, resultando favorable, determina la extinción definitiva del resto de la pena privativa de la libertad que le quedaba por cumplir al condenado" (1988: 181). La libertad condicional se considera como una forma de cumplimiento de la pena, establecida en la última de las fases del sistema progresivo y que tendrá lugar en la medida en que el sentenciado haga uso de ella y, en caso de incumplimiento, puede prolongarse la ejecución hasta la totalidad de la pena impuesta. Además, la Corte Constitucional también ha resaltado, al referirse a esta figura que "la libertad condicional es uno de esos logros del derecho penal, que busca evitar la cárcel a quien ya ha logrado su rehabilitación y por lo tanto puede reincorporarse a la sociedad" (Sentencia C-806 de 2002). 
La naturaleza de esta figura jurídica, radica en entender que, después de haber pagado una parte de la pena de prisión en un centro penitenciario o carcelario, como igualmente en prisión domiciliaria, el recluso o a quien recaiga la condena, pueda disfrutar de la libertad bajo ciertas obligaciones, con el fin de que el beneficiado se integre nuevamente a la sociedad. En el análisis de esta figura como subrogado penal, la refiere con un doble significado:

tanto moral como social; lo primero, porque estimula al condenado que ha dado muestra de su readaptación, y lo segundo, porque motiva a los demás convictos a seguir el mismo ejemplo, con lo cual, se logra la finalidad rehabilitadora de la pena (Corte Constitucional, Sentencias T-019/17. 2017; C-806/02. 2002)

Partiendo de que la Ley 65 de 1993 acoge dentro de su art. 144 un sistema progresivo, y dentro de sus periodos establecido, es precisamente el último el que puede llevar a que la persona condenada pase este periodo en fuera de la cárcel a través de la figura de la libertad condicional. Condicional porque está sujeta a los requisitos y unas obligaciones como lo establece la Ley 599 de 2000. Luego es una forma de continuar cumpliendo la totalidad de la pena que se le ha impuesto.

\subsection{Fundamento de la libertad condicional}

En un ejercicio de derecho comparado, entre España y Colombia, esta figura ha generado duda en el mundo jurídico, esta surge, para el caso español, de la interpretación de si es posible considerarla como un derecho subjetivo o como un beneficio de la persona condenada (Tébar, 2004), con respecto al segundo caso, es potestativo, porque admite cierta discrecionalidad por parte del juez de vigilancia penitenciaria mientras que, en el primer caso, debe otorgarse una vez constatados los requisitos de concesión.

Para el caso colombiano la Corte Constitucional ha señalado claramente que:

El fundamento que inspira estos subrogados penales es el derecho que tiene todo condenado a su resocialización, pues como ya lo ha expresado esta Corporación "lo que compromete la existencia de la posibilidad de resocialización no es la drástica incriminación de la conducta delictiva, sino más bien la existencia de sistemas que, como los subrogados penales y los sistemas de redención de la pena, garanticen al individuo que rectifica y en ruta su conducta, la efectiva reinserción en la sociedad" (Corte Constitucional. Sentencia C-806/02. 2002).

\section{EXCLUSIÓN DE LA LIBERTAD CONDICIONAL. 2000-2014}

Es importante hacer un recorrido entre el 2000, fecha en que se expidió el Código Penal y el 2014, cuando se hace la modificación, entre otras, a figuras como la libertad condicional, lo que permite contextualizar la normatividad que realizó exclusiones para algunos delitos y, como consecuencia, la negativa a acceder al subrogado en estudio. Si bien el artículo 64 del Código Penal, nos dice que, frente a otorgar la libertad condicional, se establece la procedencia de ciertos requisitos como lo son el objetivo y el subjetivo, pese a cumplirse el legislador ha establecido casos en los cuales este no es procedente como son:

a. Art. 11 de la Ley 733 de 2002 que trata de la exclusión de beneficios y subrogados.

Cuando se trate de delitos de terrorismo, secuestro, secuestro extorsivo, extorsión, y conexos, no procederán las rebajas de pena por sentencia anticipada y confesión; ni se concederán los subrogados penales o mecanismos sustitutivos de la pena privativa de la libertad de condena de ejecución condicional o suspensión condicional de ejecución de la pena, o libertad condicional (Ley 733, 2002).

b. Art. 199 de la Ley 1098 de 2006 que trata de Beneficios y mecanismos sustitutivos.

Cuando se trate de los delitos de homicidio o lesiones personales bajo modalidad dolosa, delitos contra la libertad, integridad y formación sexuales, o secuestro, cometidos contra niños, niñas y adolescentes, se aplicarán las siguientes reglas.... 5. No procederá el subrogado penal de Libertad Condicional, previsto en el artículo 64 del Código Penal (Ley 1098, 2006). 
c. Art. 26 de la ley 1121 de 2006, Exclusión de beneficios y subrogados:

Cuando se trate de delitos de terrorismo, financiación de terrorismo, secuestro extorsivo, extorsión y conexos, no procederán las rebajas de pena por sentencia anticipada y confesión, ni se concederán subrogados penales o mecanismos sustitutivos de la pena privativa de la libertad de condena de ejecución condicional o suspensión condicional de ejecución de la pena, o libertad condicional (Ley 1121, 2006).

d. Artículo 32 Ley 1142 de 2007. Exclusión de los beneficios y subrogados penales. El artículo 68 A del Código Penal quedará así:

No se concederán los subrogados penales o mecanismos sustitutivos de la pena privativa de libertad de suspensión condicional de la ejecución de la pena o libertad condicional; tampoco la prisión domiciliaria como sustitutiva de la prisión; ni habrá lugar a ningún otro beneficio o subrogado legal, judicial o administrativo, salvo los beneficios por colaboración regulados por la ley, siempre que esta sea efectiva, cuando la persona haya sido condenada por delito doloso o preterintencional dentro de los cinco (5) años anteriores o cuando haya sido condenado por uno de los siguientes delitos: cohecho propio, enriquecimiento ilícito de servidor público, estafa y abuso de confianza que recaigan sobre los bienes del Estado, concusión, prevaricato por acción y por omisión, celebración de contrato sin el cumplimiento de los requisitos legales, lavado de activos, utilización indebida de información privilegiada, interés indebido en la celebración de contratos, violación del régimen de inhabilidades e incompatibilidades, tráfico de influencias, peculado por apropiación y soborno transnacional (Ley 1142, 2007).

e. Artículo 68A. Ley 1453 de 2011. Exclusión de los beneficios y subrogados penales.

No se concederán los subrogados penales o mecanismos sustitutivos de la pena privativa de libertad de suspensión condicional de la ejecución de la pena o libertad condicional; tampoco la prisión domiciliaria como sustitutiva de la prisión; ni habrá lugar a ningún otro beneficio o subrogado legal, judicial o administrativo, salvo los beneficios por colaboración regulados por la ley, siempre que esta sea efectiva, cuando la persona haya sido condenada por delito doloso o preterintencional dentro de los cinco (5) años anteriores o cuando haya sido condenado por uno de los siguientes delitos: cohecho propio, enriquecimiento ilícito de servidor público, estafa y abuso de confianza que recaigan sobre los bienes del Estado, concusión, prevaricato por acción y por omisión, celebración de contrato sin el cumplimiento de los requisitos legales, lavado de activos, utilización indebida de información privilegiada, interés indebido en la celebración de contratos, violación del régimen de inhabilidades $\mathrm{e}$ incompatibilidades, tráfico de influencias, peculado por apropiación y soborno transnacional (Ley 1453, 2011).

f. Artículo 13 de la ley 1474 de 2011. exclusión de beneficios en los delitos contra la administración pública relacionados con corrupción.

No se concederán los subrogados penales o mecanismos sustitutivos de la pena privativa de libertad de suspensión condicional de la ejecución de la pena o libertad condicional; tampoco la prisión domiciliaria como sustitutiva de la prisión; ni habrá lugar a ningún otro beneficio o subrogado legal, judicial o administrativo, salvo los beneficios por colaboración regulados por la ley, siempre que esta sea efectiva, cuando la persona haya sido condenada por delito doloso o preterintencional dentro de los cinco (5) años anteriores.

Tampoco tendrán derecho a beneficios o subrogados quienes hayan sido condenados por delitos contra la Administración Pública, estafa y abuso de confianza que recaigan sobre los bienes del Estado, utilización indebida de información privilegiada, lavado de activos y soborno transnacional (Ley 1474, 2011).

En resumidas cuentas, podemos encasillar las conductas punibles que el legislador Colombiano considera más grave y por ende no pueden acceder a dicho subrogado. Como se muestra en el siguiente cuadro: 
TABLA 1. LEYES Y CONDUCTAS PUNIBLES

\begin{tabular}{|c|c|}
\hline LEYES & CONDUCTAS PUNIBLES \\
\hline $\begin{array}{l}\text { Art. } 11 \text { de la Ley } 733 \\
\text { de } 2002 .\end{array}$ & Terrorismo, secuestro, secuestro extorsivo, extorsión, y conexos. \\
\hline $\begin{array}{l}\text { Art. } 199 \text { de la Ley } \\
1098 \text { de } 2006\end{array}$ & $\begin{array}{l}\text { Homicidio o lesiones personales bajo modalidad dolosa, delitos contra la libertad, inte- } \\
\text { gridad y formación sexuales, o secuestro, cometidos contra niños, niñas y adolescentes... }\end{array}$ \\
\hline $\begin{array}{l}\text { Art. } 26 \text { de la ley } \\
1121 \text { de } 2006\end{array}$ & Terrorismo, financiación de terrorismo, secuestro extorsivo, extorsión y conexos. \\
\hline $\begin{array}{l}\text { Artículo } 32 \text { Ley } \\
1142 \text { de } 2007\end{array}$ & $\begin{array}{l}\text { Cohecho propio, enriquecimiento ilícito de servidor público, estafa y abuso de confianza } \\
\text { que recaigan sobre los bienes del Estado, concusión, prevaricato por acción y por omi- } \\
\text { sión, celebración de contrato sin el cumplimiento de los requisitos legales, lavado de } \\
\text { activos, utilización indebida de información privilegiada, interés indebido en la celebra- } \\
\text { ción de contratos, violación del régimen de inhabilidades e incompatibilidades, tráfico de } \\
\text { influencias, peculado por apropiación y soborno transnacional. }\end{array}$ \\
\hline $\begin{array}{l}\text { Artículo 68A. Ley } \\
1453 \text { de } 2011\end{array}$ & $\begin{array}{l}\text { Cohecho propio, enriquecimiento ilícito de servidor público, estafa y abuso de confianza } \\
\text { que recaigan sobre los bienes del Estado, concusión, prevaricato por acción y por omi- } \\
\text { sión, celebración de contrato sin el cumplimiento de los requisitos legales, lavado de } \\
\text { activos, utilización indebida de información privilegiada, interés indebido en la celebra- } \\
\text { ción de contratos, violación del régimen de inhabilidades e incompatibilidades, tráfico de } \\
\text { influencias, peculado por apropiación y soborno transnacional. }\end{array}$ \\
\hline $\begin{array}{l}\text { Artículo } 13 \text { de la ley } \\
1474 \text { de } 2011\end{array}$ & $\begin{array}{l}\text { (...) quienes hayan sido condenados por delitos contra la Administración Pública, estafa } \\
\text { y abuso de confianza que recaigan sobre los bienes del Estado, utilización indebida de } \\
\text { información privilegiada, lavado de activos y soborno transnacional. }\end{array}$ \\
\hline
\end{tabular}

Fuente: Elaboración propia.

\section{LA LIBERTAD CONDICIONAL EN LA LEY 1709 DE 2014}

\subsection{Antecedentes a la modificación de la libertad condicional}

Desde el periodo 2010 a finales del 2013, se presentaron varios hechos que agravaron la situación del sistema penitenciario y carcelario en Colombia, dentro de los cuales podemos destacar los siguientes:

i. Hacinamiento: Al terminar el mes de enero de 2014, el hacinamiento según informe del INPEC indicaba que "la población carcelaria y penitenciaria del país supera la capacidad de los establecimientos de reclusión, situación que se ve reflejada en el mes de enero donde se presentó una sobrepoblación de 44.557 internos(as), equivalente a un hacinamiento del 58.6\%." (Revista. Informe estadístico enero 2014. p 19). ii. El estado de emergencia carcelaria: la situación que se presentó en el sistema penitenciario de hacinamiento carcelario llevó a que se tomaran determinaciones, entre ellas se profirió; "Resolución No. 001505 del 31 de mayo del 2013 con concepto favorable del Ministerio de Justicia y del Derecho, se declara el Estado de Emergencia Penitenciaria y Carcelaria en todos los ERON y a su vez a través de la Directiva Transitoria No. 0023 del 04 de junio del 2013 se establecieron una serie de directrices y estrategias para dicha intervención, por un término de siete meses, con el fin de conjurar la situación". (Revista entre muros para la libertad 2013, p 36)

La gran vulneración de derechos fundamentales es una problemática que con frecuencia se evidencia en la sociedad colombiana (Archila, J. y Hernández, N., 2015), donde las mismas instituciones han tenido un doble papel al asumir responsabilidades, una por ser generadora y otra por no dar respuestas eficaces a las problemáticas vividas. En algunos casos por el gran número de vulneración de los 
derechos, en un grupo social en específico y bajo el ejercicio de la acción de tutela y el de petición, se han evidenciado fallas estructurales, que han generado una intervención por parte de la Corte Constitucional. Esta intervención de la Corte, ha dado paso a la declaración del Estado de Cosas Inconstitucional (en adelante ECI), en varias ocasiones. Al respecto Higuera, J. (2018), ha manifestado que:

(...) es una declaratoria de vulneración masiva, grave y generalizada de derechos fundamentales. En ella el juez constitucional determina que ha existido una transgresión masiva de los mandatos superiores, por lo tanto, esta vulneración no se reduce a un hecho concreto, sino que es realmente una irradiación de afectación (...) (p, 16).

Este fallo representa un hito, ya que el máximo juez constitucional emite un fallo estructural que tiene como facultad, soportar y agrupar a todas las personas que se encuentran en esa misma condición y que da origen a la intervención del juez (efecto inter comunis), que al enunciar $a$ todas las personas, se refiere a cada individuo, esté o no dentro de la demanda suscrita. Este tipo de fallos cuentan con elementos generales que condicionan un acompañamiento obligatorio, mediante autos de seguimiento, resultados, medidas de integración, por ende, buscan una autentica integración en los criterios de justicia validez y eficacia (Higuera, 2016). Bajo estas medidas la Corte Constitucional declaró el ECI del sistema penitenciario y carcelario, cuando afirmó que:

En las condiciones de hacinamiento y deterioro de la infraestructura penitenciaria y carcelaria, así como de los servicios que se presentan en cada establecimiento, la posibilidad de que se den tratos crueles, inhumanos e indignos aumenta notoriamente. La deshumanización de las personas en los actuales contextos carcelarios es evidente. Las condiciones en que son mantenidas las personas privadas de la libertad, por ejemplo, suelen ser relacionadas con las condiciones en que existen algunos de los animales relegados en nuestra sociedad a los lugares de suciedad (Corte Constitucional, sentencia T-388/13, 2013).
Estas situaciones y la anunciada reforma a la Ley 599 de 2000 y 65 de 1993, a través de la Ley 1709 de 2014, hacían prever mejores condiciones para la población carcelaria, así, por ejemplo, una noticia periodística de la revista Semana (2014) anunciaba que "Los presos están hacinados en las cárceles de Colombia y la solución que el gobierno le quiere dar a ese problema es dejar libres a 9.000 reclusos que cumplen con ciertas condiciones". En ese sentido lo más importante de la reforma, fue el aumento del aspecto objetivo para los subrogados penales libertad condicional y suspensión de la ejecución de la pena así como también para la pena sustitutiva de prisión, como lo es, la prisión domiciliaria.

\subsection{Modificación por la Ley 1709 de 2014 a la libertad condicional}

La Ley 1709 de 2014, tan esperada por la población condenada y de la que aparentemente muchos se pensaban beneficiar, hasta el mismo gobierno aspiraba a nivelar la población y bajar el índice de hacinamiento, no resultó como se esperaba. Seis años después se mantienen los niveles de hacinamiento en un promedio del $50 \%$, según se desprende del seguimiento a las revistas mensuales expedidas por el INPEC.

El art. 30 de la Ley 1709 de 2014 modificó el artículo 64 de la Ley 599 de 2000, respecto de la libertad condicional, dirigido a ampliar el aspecto objetivo y subjetivo para que el sentenciado pudiese acceder más tempranamente a su libertad, así:

El juez, previa valoración de la conducta punible, concederá la libertad condicional a la persona condenada a pena privativa de la libertad cuando haya cumplido con los siguientes requisitos:

1. Que la persona haya cumplido las tres quintas $(3 / 5)$ partes de la pena.

2. Que su adecuado desempeño y comportamiento durante el trata $\neg$ miento penitenciario en el centro de reclusión permita suponer fundadamente que no existe necesidad de continuar la ejecución de la pena.

3. Que demuestre arraigo familiar y social. 
Corresponde al juez competente para conceder la libertad condicional establecer, con todos los elementos de prueba allegados a la actuación, la existencia o inexistencia del arraigo.

En todo caso su concesión estará supeditada a la reparación a la víctima o al aseguramiento del pago de la indemnización mediante garantía personal, real, bancaria o acuerdo de pago, salvo que se demuestre insolvencia del condenado.

El tiempo que falte para el cumplimiento de la pena se tendrá como periodo de prueba. Cuando este sea inferior a tres años, el juez podrá aumentarlo hasta en otro tanto igual, de considerarlo necesario (Ley 1709 de 2014; Corte Constitucional, Sentencia C-757$14 / 2013$ ) (subrayas fuera del original).

Como se observa, el aspecto objetivo se amplió, este paso de $2 / 3$ partes a las $3 / 5$ partes, donde la persona que descuente condena y cumpla con las $3 / 5$ partes de la pena impuesta, a la que se llega por descuento físico, sumado a la redención de pena por trabajo, estudio y enseñanza que le haya decretado un juez de ejecución de penas y medidas de seguridad, y además cumpla con el aspecto subjetivo de acuerdo a los parámetros de los numerales 2 y 3 , en el que refiere el cumplimiento del tratamiento penitenciario. Esto supone que las autoridades carcelarias han realizado un seguimiento del progreso individual de cada uno de los internos, en las distintas fases que consagra el art. 144 de la Ley 65 de 1993 cuya última fase es la de confianza, que está dirigida a que coincida con la libertad condicional. (Corte Constitucional, Sentencia T-1093/05, 2005). Esa confianza está direccionada a que la persona que acreedora al subrogado cumpla las obligaciones adquiridas en el acta de compromiso suscrita ante el juez de ejecución de penas y medidas de seguridad al momento de obtener su libertad.

Igualmente, el art. 64 adicionó en el aspecto subjetivo la demostración del arraigo familiar y social. Siendo esta la última modificación a la figura de la libertad condicional, dándole al juez un amplio margen para otorgarlo.

El art. 32 de la Ley 1709 de 2014, modificó el Artículo 68A. Exclusión de los beneficios y subrogados penales.
No se concederán; la suspensión condicional de la ejecución de la pena; la prisión domiciliaria como sustitutiva de la prisión; ni habrá lugar a ningún otro beneficio, judicial o administrativo, salvo los beneficios por colaboración regulados por la ley, siempre que esta sea efectiva, cuando la persona haya sido condenada por delito doloso dentro de los cinco (5) años anteriores...

Parágrafo $1^{\circ}$. Lo dispuesto en el presente artículo no se aplicará a la libertad condicional contemplada en el artículo 64 de este Código, ni tampoco para lo dispuesto en el artículo 38G del presente Código."

Con lo dispuesto en el parágrafo 1 del art. $68^{\text {a }}$ se suprime el subrogado penal de la libertad condicional de las prohibiciones de exclusión de beneficios, buscando para ese momento que el mayor número de sentenciados accediera a la figura jurídica en comento y ayudara a aliviar el hacinamiento que para el año 2013 se podía considerar de gravedad y que llevó a que la Corte por segunda vez declarará el estado de cosas inconstitucionales (Corte Constitucional, Sentencia T-388/13, 2013).

Así también lo ratificó la Corte Suprema de Justicia al afirmar que:

En consecuencia, lo que en últimas hizo el parágrafo $1^{10}$ del artículo 32 de la Ley 1709 de 2014 fue establecer que la libertad condicional prevista en el artículo 64 del Código Penal no se encuentra vedada para aquellos que hubieran sido condenados por los punibles relacionados en el párrafo $1^{1} \stackrel{-}{ }$ ibídem, dentro de los cuales no se incluyeron aquellos que atenten contra la libertad, integridad y formación sexual cuando la víctima sea un menor de edad, de manera que, resulta apenas obvio, cuando se trate de este tipo de infracciones, la prohibición continúa vigente (Corte Suprema de Justicia, Sala de Casación Penal, Proceso No. 85044, sentencia del 21 de abril de 2016) (Tribunal Superior del Distrito Judicial de Pereira Risaralda, Sala de Decisión Penal, Radicado 660016000105201100014 . Acta No 1147 del 13 de diciembre de 2018). 
Con respecto a las demandas de inconstitucionalidad que se han realizado a este artículo, se pude resaltar algunas consideraciones que ha realizado la Corte frente a alguno de sus apartes. Así, explicó en su oportunidad que el "verbo conceder, significa que la ley impone el deber de otorgarla a aquellos condenados que hayan cumplido los requisitos establecidos en la norma" (Corte Constitucional, Sentencia C-757/14, 2014, y Sentencia C-194/05, 2005); con respecto a las palabras subrayadas "previa valoración de la conducta punible" la Corte en su fallo indicó que:

(...) la nueva redacción le impone el deber al juez de otorgar la libertad condicional una vez verifique el cumplimiento de los requisitos, cuando antes le permitía no otorgarlos. Por otra parte, la nueva disposición amplía el objeto de la valoración que debe llevar a cabo el juez de ejecución de penas más allá del análisis de la gravedad de la conducta punible, extendiéndola a todos los aspectos relacionados con la misma (Corte Constitucional, Sentencia C-757/14, 2014).

En el mismo fallo agregó que las valoraciones de la conducta punible que hagan los jueces de ejecución de penas y medidas de seguridad para decidir sobre la libertad condicional de los condenados "debe tener en cuenta todas las circunstancias, elementos y consideraciones hechas por el juez penal en la sentencia condenatoria, sean éstas favorables o desfavorables al otorgamiento de la libertad condicional" (Corte Constitucional, Sentencia C-757/14, 2014 y Sentencia T-640/17, 2017), para concluir que los jueces de ejecución de penas y medidas de seguridad deben aplicar la constitucionalidad condicionada de la expresión "previa valoración de la conducta punible", en todos aquellos casos en dicho condicionamiento les sea más favorable a los condenados.

En caso de revocarse el subrogado de la libertad condicional el sentenciado deberá de terminar de pagar la pena que se le había impuesto en la sentencia condenatoria, hasta que la cumpla en su totalidad, sin derecho a volver a solicitar el subrogado de la libertad condicional, siendo procedente únicamente acceder a la redención de pena por trabajo, estudio y enseñanza dirigidos a cumplir el fin de la pena, la resocialización.
Frente a las siguientes acciones de otorgamiento y de revocatoria, la implicación de los requisitos objetivos y subjetivo están encausados en ciertos problemas interpretativos en su valoración. Consideramos ahora hacer una distinción y, por consiguiente, una clarificación de los requisitos propiamente dichos, a los que definiremos como aquellas pautas de aplicación que han sido dictaminadas por el legislador en el sentido punitivo, que tienen como función determinar un criterio relativo respecto a la duración de la pena. Para el requisito objetivo en aspectos generales, se hace una revisión de la pena impuesta y de su cumplimiento efectivo, nos podemos referir a esta en dos sentidos: (i) previo a otorgar la libertad condicional y (ii) posterior a ser otorgada, en estos dos casos, se refiere en sí al quantum de la pena y su cumplimiento. Para el aspecto subjetivo, se consideran los criterios íntimos y personales del sentenciado, un criterio altamente criticable, ya que depende de comportamiento "social" de quien se le otorgó la libertad condicional y la valoración subjetiva del juez. Consideramos que, en este último aspecto, el examen que se realice por el juez, tiene que ser muy exigente, para determinar si el condenado es merecedor de continuar con el subrogado, o se considera que no ha cumplido con las exigencias necesarias para gozar del beneficio.

Esta investigación plantea que es altamente criticable, ya que la valoración del juez se funda por el "arraigo" que tiene la persona condenada con la sociedad, en este caso, la consideración del individuo y el sentido de su acción individual se ve limitado al ejercicio que se realiza como actor en un colectivo social. En este ejercicio el condenado ve necesariamente su actuar en lo que es y en lo que debe ser, guiado por preferencias, necesidades y elecciones que debe ir configurando la persona en su nuevo contexto. En ese sentido si, como decía Sartre l' enfer, c'est les autres, el contexto social donde la persona se ve ubicada, está dado necesariamente por el accionar de otras personas, y se termina realizando juicios de la persona situada en el contexto social. Weber (1999) explica que las estructuras sociales (estado, familia, centros penitenciarios y carcelarios, juntas de acción comunal, etc.) son estrictamente; “(...) desarrollos y entrelazamientos de acciones específicas de personas individuales, ya que tan sólo éstas pueden ser sujetos de una acción orientada por su sentido" (p. 15). 
Sin embargo, el legislador, al momento de señalar los aspectos (subjetivos) necesarios para continuar con la otorgación del subrogado penal, no exploro, u omitió, el análisis profundo de la acción humana, encaminada esta al ejercicio de su obrar como la unidad última. Entonces ¿Qué pasaría si una persona condenada, encuentra su actuar en el aislamiento social? ¿Este actuar no es válido y provisto por los legisladores y los jueces a la hora de realizar el examen pertinente? 0 , mejor aún ¿Entre más sociable más beneficios? Son inquietudes que surgen, y que por ende consideramos que el examen muy exigente del juez, tiene que ir de la mano con estudios sociológicos, psicológicos, filosóficos, entre otros, y que este examen es así mismo una valoración individual y no comparativa con otros casos. Esto porque el individuo en sociedad en único e irrepetible, además de esto consideramos que este examen debe orientarse a la humanización de la pena, y a preservar la garantía fundamental de sus derechos, en este caso, la libertad y el desarrollo individual de casa persona.

\subsection{Otorgamiento de la libertad condicional}

Sea lo primero mencionar que el otorgamiento de la libertad condicional está en cabeza del Juez de Ejecución de Penas y Medidas de Seguridad de acuerdo a lo establecido en el numeral 3 del art. 38 de la Ley 906 de 2004. El art. 471 de la obra en cita establece los documentos que se deben aportar a la solicitud de libertad condicional que hace el sentenciado, su apoderado de confianza o un defensor público designado por la defensoría del Pueblo que a la letra dice:

(...) acompañando la resolución favorable del consejo de disciplina, o en su defecto del director del respectivo establecimiento carcelario, copia de la cartilla biográfica y los demás documentos que prueben los requisitos exigidos en el Código Penal, los que deberán ser entregados a más tardar dentro de los tres (3) días siguientes (Ley 906 de 2004, art. .471).

\subsection{Revocatoria}

La revocatoria de los subrogados penales (condena de ejecución condicional y libertad condicional) también se encuentra en cabeza del Juez de Ejecución de Penas y Medidas de
Seguridad. En aspectos generales obedece al incumplimiento a las obligaciones adquiridas por el sentenciado a la hora de firmar el acta de compromiso, entre estas encontramos: 1. Informar todo cambio de residencia. 2. Buena conducta. 3. Reparar los daños, a menos que se demuestre que está en imposibilidad económica. 4. Comparecer personalmente ante la autoridad judicial. 5. No salir del país sin previa autorización del funcionario. (Ley 599 de 2000, Art. 65). En la mayoría de casos su cumplimiento está sujeto al tiempo que resta por cumplir efectivamente la sentencia, sin que sea inferior a dos años ni mayor a cinco.

Dicha revocatoria podrá hacerse de oficio o a petición de los encargados de la vigilancia, o de la misma víctima, los motivos de la revocatoria se pondrán en conocimiento del sentenciado para que dentro de un término de tres días presente las explicaciones del caso y el Juez resuelva dentro de los diez días siguientes. Las decisiones que adopten serán objeto de recurso de reposición y apelación, esta última se surtirá ante el juez que profirió la condena de primera o única instancia (Ley 906 de 2004, Arts. 477 y 478).

\section{IMPACTO DE LA LIBERTAD CONDICIONAL PERIODO 2014- 2020}

El mismo INPEC en sus estadísticas hace una valoración de la población a su en el periodo 2014-2018, así:

(...) el año 2014 cerró con una considerable caída en el número de internos(as) de -5,3\% (6.409) producto de la aplicación de la Ley 1709 de 2014; sin embargo, en 2015 la cifra se estabiliza y retoma su tendencia creciente, culminando el año con un incremento porcentual de 6,0\% (6.821). En 2016 se observa una tendencia decreciente, cerrando con una variación porcentual de $-1,6 \%$ (1.912). En 2017 la variación continua en la misma línea, concluyendo en $-3,2 \% \quad(-3.782$ personas menos). En 2018 la propensión cambia nuevamente de sentido y registra incremento de 3,3\% (3.763). (INPEC, 2020: 25).

Al analizar la información del mes de diciembre de 2019 se encontró con una población privada de la libertad de 123.802 (INPEC, 2020: 17), incrementándose con respecto al mismo mes 
del año anterior en $3.7 \%$, es decir, 6.799 personas (INPEC, 2020) con un índice de hacinamiento del $54.3 \%$.

En el mismo informe se ilustra la capacidad que tienen los centros carcelarios y penitenciarios para albergas a las personas, como también nos ilustra la cantidad internos y por último el índice de hacinamiento presente en esos años (INPEC, 2020: 38).

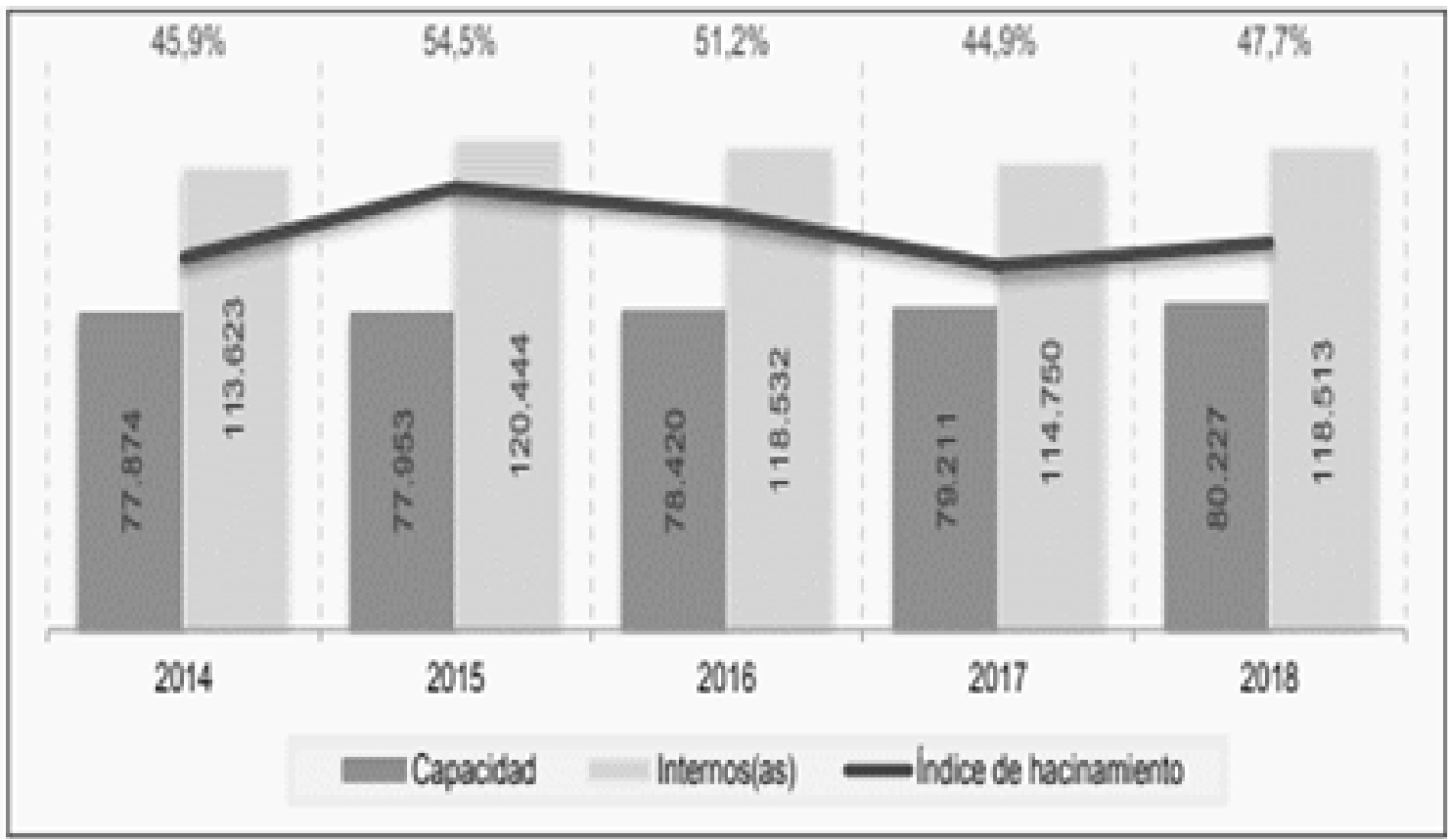

Gráfico 1. Fuente: GEDIP -2018.

Conociendo el comportamiento de la población carcelaria, y con el fin de aproximarnos a las cifras de los reclusos que solicitan la libertad condicional y su otorgamiento, se cuantificó la información extraída de las revistas De entre Muros para la libertad, años 2014, 2015 y 2016. En este caso la publicación de 2017 no trae información de libertad condicional por tal razón se acudió a "series históricas 2017" (INPEC, $2017 \mathrm{~b})$ donde solo se registran algunos meses, enero (775), febrero (888), marzo (1.142), abril (872) mayo (831), junio sin información, julio (815), agosto (1.265), septiembre (1.322) octubre y noviembre sin información y diciembre (1.065) para un total en los nueve meses de 8.975.

La información que se registra en INPEC (2018) es limitada. Esta refiere, en la tabla 59, a los subrogados penales (p, 71), donde mes a mes se calcula el número de libertades condicionales, sin que se aclare si las mismas corresponden a solicitud o las ya otorgadas por los jueces de ejecución de penas y medidas de seguridad. Por lo tanto la información de las dos últimas revistas es sesgada porque no permite hacer seguimiento a la figura en estudio.

Como no se ha expedido al mes de marzo del 2020 el informe del INPEC de 2019, y con el fin de rastrear la información de libertades condicionales otorgadas, se acudió a los tableros mes a mes de "series históricas" (INPEC, 2019b). La sumatoria se ilustrará en la tabla 2.

Del año 2019, tenemos: enero (646), febrero (1001), marzo (858), abril (955), mayo (1.196), junio (913), julio (776) agosto no registra, septiembre (925), octubre no registra, noviembre 
(729) y diciembre (1.125) para un total en los diez meses de 9.124. Enero del 2020 registra 864 casos de libertad condicional (INPEC, 2019b).

Un ejemplo de tablero del Inpec de series históricas se registra en la figura (2) siguiente. En este se evidencia el seguimiento mes a mes a los subrogados penales. En su primera parte se relaciona las regionales INPEC a nivel de Colombia, y en la columna siguiente, específicamente frente a la libertad condicional, muestra las otorgadas en el mes de enero de 2019, para hombres y mujeres con una sumatoria de todas las regionales de 646, y así sucesivamente durante todo el año.

\section{Subrogados penales \\ Enero 31 de 2019}

\begin{tabular}{l|c|c|c|c|c}
\multirow{2}{*}{\multicolumn{1}{c|}{ Regional }} & \multicolumn{3}{c|}{ Libertad Condicional } & \multicolumn{2}{c}{ Suspensión de } \\
\cline { 2 - 6 } & Hombre & Mujer & Subtotal & Hombre & Mujer \\
\hline Central & 175 & 17 & 192 & 16 & 3 \\
\hline Occidente & 150 & 22 & 172 & 10 & 0 \\
\hline Norte & 71 & 4 & 75 & 8 & 0 \\
\hline Oriente & 49 & 3 & 52 & 3 & 1 \\
\hline Noroeste & 52 & 11 & 63 & 7 & 1 \\
\hline Viejo Caldas & 78 & 14 & 92 & 3 & 0 \\
\hline Total Regional & 575 & 71 & 646 & 47 & 5 \\
\hline
\end{tabular}

Fuente. SISIPEC WEB

Nota Explicativa. Los Subrogados Penales son beneficios adquiridos conforme a lo dis condena.

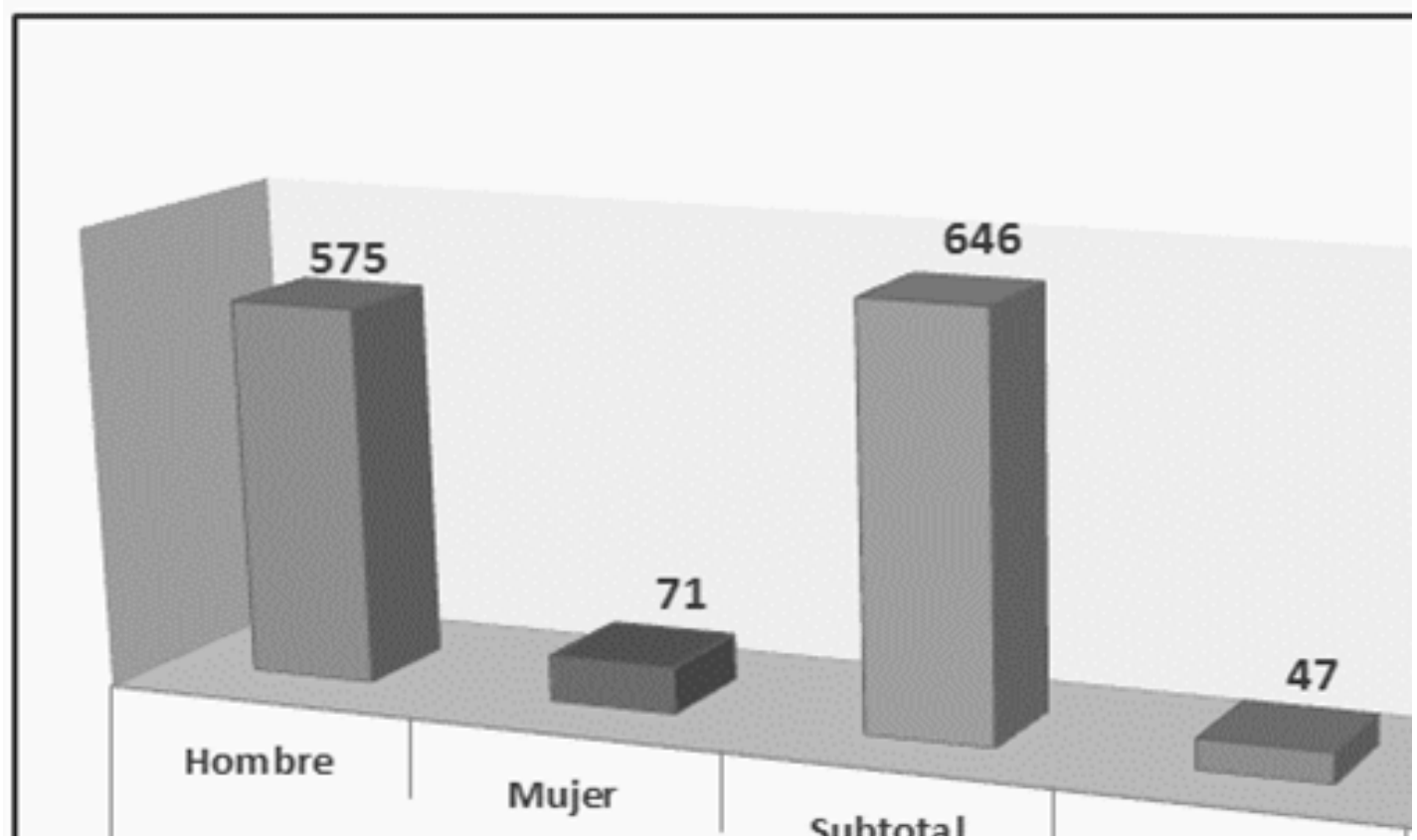

Gráfico 2. Fuente: SISIPEC WEB. 
TABLA 2. SOLICITUDES Y OTORGAMIENTOS DE LIBERTAD CONDICIONAL (2014-ENERO 2020)

\begin{tabular}{|l|l|l|l|l|l|}
\hline AÑ & $\begin{array}{l}\text { POBLACIÓN } \\
\text { CONDENADA }\end{array}$ & SOLICITUD & OTORGADAS & $\begin{array}{r}\text { NO } \\
\text { CONCEDIDAS }\end{array}$ & EN ESPERA \\
\hline 2014 & 75.526 & 15.965 & 14.152 & No aclara & \\
\hline 2015 & 76.494 & 15.356 & 10.043 & 798 & 4.515 \\
\hline 2016 & 80.693 & 15.475 & 11.230 & 680 & 3.565 \\
\hline 2017 & 77.973 & No refiere & 8.975 & No refiere & No refiere \\
\hline 2018 & 78.679 & No refiere & 9.541 & No refiere & No refiere \\
\hline 2019 & 82.605 & No refiere & 9.124 & No refiere & No refiere \\
\hline 2020 & 83.242 & No refiere & 864 mes de enero & No refiere & No refiere \\
\hline
\end{tabular}

Fuente: Elaboración del autor. Información INPEC.

En seis (6) años que han transcurrido, después de la expedición de la Ley 1709, la población condenada y privada de la libertad ha oscilado entre 75.526 y 83.242 y lo máximo que ha llegado a otorgarse, por año, el subrogado de la libertad condicional es 14.152 personas condenadas, cifra que corresponde al año 2014, fecha en que se expidió la mencionada ley. De ahí en adelante su registro es relativamente bajo y no se compadece con el número de personas condenadas.

Es importante también analizar en la información del INPEC, cuántas personas están solicitando su libertad por pena cumplida para, con ello, tratar de aproximarnos a si son las mismas que no pueden acceder a la libertad condicional porque no cumplen el aspecto subjetivo establecido en el art. 64 del Código Penal o porque están, posiblemente. dentro de las prohibiciones establecidas por la ley. Desafortunadamente, el estudio solo puede realizarse sobre los años 2014, 2015 y 2016, los informes del INPEC de los años subsiguientes optaron por guardar silencio frente a esta solicitud que hacen las personas que cumplen la totalidad de la pena impuesta.

TABLA 3. SOLICITUDES Y OTORGAMIENTO DE LIBERTAD POR PENA CUMPLIDA

\begin{tabular}{|l|l|l|l|l|}
\hline AÑO & \multicolumn{1}{|c|}{ SOLICITUD } & \multicolumn{1}{|c|}{ OTORGADAS } & NO CONCEDIDAS & EN TRÁMITE \\
\hline 2014 & 5.158 & 4.791 & No establece & No registra \\
\hline 2015 & 5.508 & 4.281 & No establece & No registra \\
\hline 2016 & 5.979 & 5.138 & No establece & 841 \\
\hline
\end{tabular}

Fuente: Elaboración propia, con base en información del INPEC. 
Las solicitudes reportadas en los tres años referidos en la tabla, indican que más de 6.000 sentenciados se encuentran privados de la libertad, cumpliendo la totalidad de la pena sin poder acceder al subrogado de la libertad condicional. A ellos se les niega el fin de la pena y la resocialización, posiblemente olvidando que los sustitutivos de la pena de prisión buscan garantizar:

i) el principio de igualdad; ii) los derechos fundamentales intangibles de los reclusos como son el debido proceso, el derecho de defensa y el acceso a la administración de justicia; iii) se materializan los fines de resocialización de la pena; iv) genera un alivio en términos de hacinamiento y sobrepoblación carcelaria; y v) humaniza el sistema penitenciario y carcelario del país (Corte Constitucional, Sentencia C-328/16, 2016).

\section{LA VALIDEZ Y LA EFICACIA DE LA NORMA}

Al recurrir a un examen de validez y de eficacia de la norma que regula la libertad condicional, se advierte un panorama desalentador en cuanto a sus resultados. Por un lado, su validez se cumple a satisfacción; debido a que es promulgada por un órgano competente y es resultado de un procedimiento autorizado, que, previo a un examen de inconstitucionalidad, que entendió su compatibilidad con otras normas de similar rango, la Constitución y los tratados internacionales a los cuales Colombia por bloque de constitucionalidad. ha adherido.

Por otro lado, para determinar la eficacia de una norma jurídica y la obediencia de esta, basta con realizar un análisis empírico (sociológico) de la norma en la sociedad determinada; en este caso se busca identificar lo descrito por las normas y su aplicabilidad en la vida practica de las personas. Este examen de eficacia tiene más éxito cuando la norma creada, se atiende con mayor naturaleza por parte de la población, es decir su aceptabilidad se hace de manera espontánea. Al contrario, si la norma necesita de coacción para su cumplimiento, estas son normas con un alto índice de ineficacia. El problema surge, cuando una norma que bajo su creación es válida no cumple a satisfacción o es reprochable por parte de los individuos a los que va dirigida. Es decir que puede ser válida, pero es ineficaz.

En el caso concreto, se puede afirmar que si bien la norma es válida, pasó el examen de creación de autoridad competente, de procedimiento indicado y de publicación, es altamente ineficaz. Bajo el examen de los datos obtenidos del INPEC, la población carcelaria que accede a dicho beneficio, se reduce con el paso de los años, lo que demuestra que la política criminal no cumple a satisfacción con la mitigación y la humanización de la sanción punitiva. Esta conclusión surge del índice de aprobación y accesibilidad a la libertad condicional, pues en los seis años posteriores a la expedición de la Ley 1709 , la población que se encuentra privada de la libertad y pagando una condena ha oscilado entre 75.526 y 83.242, mientras los datos nos indican que las personas que acceden a este beneficio no alcanzan ni el $20 \%$, reduciendo el número a tan solo 14.152 personas. Como ya se anotó, esto se debe principalmente en la libertad de la valoración subjetiva que realiza el juez, respecto al arraigo social que tiene la persona con su sociedad.

\section{CONCLUSIÓN}

El último suplicio de un condenado empieza cuando cree que puede obtener su libertad condicional porque ha alcanzado su resocialización para vivir nuevamente en la comunidad. Esto al considerar que el tiempo permanecido en privación de su libertad es el complemento de su buen actuar disciplinado, el máximo respeto de las normas del sistema penitenciario y carcelario, la buena convivencia con las personas que de paso concurren en las mismas condiciones de vida y la actividad desplegada a través del trabajo, estudio o enseñanza. Pero con las paradojas institucionales, la esperanza de poder terminar la suspensión de sus derechos (libertad) se ve socavado, más aun, cuando existe un punto final por las diversas interpretaciones de la norma y las marcadas contradicciones en la misma. Donde el operador judicial atiende con criterio negativo su solicitud, cuya consecuencia es el cumplimiento total de la condena.

La expectativa de una resocialización definitiva se ve terminada cuando se conoce la expedición de leyes como el caso de la Ley 1709 
de 2014 que, como todas las que le han precedido, solo ha logrado mantener $y$ aumentar el hacinamiento penitenciario y carcelario. No basta con los llamados de atención enrostrados por la Corte Constitucional, como lo ha manifestado últimamente en sus sentencias T-388 de 2013 y T-762 de 2015, ni mucho menos cuando la Corte Constitucional ha puntualizado en la queja generalizada de las personas privadas de la libertad, no solo por la excesiva población, sino por la violación a varios derechos fundamentales como la salud, la vida, la integridad personal, su dignidad, entre otros, que son un limitante para alcanzar la resocialización.

La contradicción de la ley en cita radicó en haber creado una expectativa tanto en las personas privadas de la libertad con condena como en sus familias, al haber posibilitado que el aspecto objetivo fuera más benigno en el tiempo de la restricción de locomoción, al cuantificarla en las $3 / 5$ partes de la pena y no en las $2 / 3$ partes, que contraía la Ley 599 de 2000. Júbilo pasajero en atención a que el articulado de la misma, condensó unos sinsabores focalizados en la taxatividad exagerada de conductas por las cuales se restringió anticipadamente la resocialización del sentenciado, amén de las exigencias inconcebibles para la gran mayoría en torno al aspecto subjetivo, puntualizado en el arraigo familiar y social de los cuales el operador judicial encargado de hacer cumplir la pena, con desbordada interpretación la aplica, dejando en el limbo al ajustado a que permanezca bajo la vigilancia del ente destinado para tal fin, hasta el cumplimiento total de la condena.

Una política criminal tiene que estar dirigida a una real resocialización creando, al menos para la población totalmente marginada a puertas de obtener la libertad condicional, un domicilio temporal. Además, supliendo las necesidades básicas de alimentación, atención en salud, preparación al campo laboral, anudado todo a unos convenios patronales que lo incentiven a la permanencia en una vida normal, más nunca desprotegido de dichos factores. Lo único que han demostrado la ausencia de prácticas realmente resocializadoras en la ejecución de la pena es la reincidencia en la conculcación de la misma conducta punible o de otras diversas, convirtiendo al sistema en un ciclo sin solución efectiva.

La expedición de la Ley 1709 no causó permanente impacto en las personas privadas de la libertad ni en sus familiares, pues si en su primer año de vigencia se beneficiaron un significativo número de condenados, que bajó en más de 7 puntos el hacinamiento carcelario, en lo sucesivo se tornó ineficaz. Esto, en gran parte, por las diversas interpretaciones posteriores que se le hicieron al contenido y alcance del articulado en su conjunto, volviendo a extremos inimaginables de hacinamiento, el cual se está, en la media, igual o superior al $50 \%$, lo que vuelve repetitiva la violación masiva de los derechos fundamentales y la demostración ineficaz de decisiones tomadas, hasta ahora, por las ramas del poder público.

El subrogado de la libertad condicional establecido como el último eslabón del sistema progresivo, en sí mismo es una motivación para el condenado en pro de lograr su libertad de locomoción en el tiempo instituido en la figura estudiada, la cual no debe tener limitaciones en el aspecto subjetivo, quedando su control una vez obtenida la libertad en cabeza del Estado a través de programas que permitan una verdadera integración a la sociedad.

\section{BIBLIOGRAFÍA}

- Archila, J. y Hernández, N., 2015Subrogados y hacinamiento carcelario. Respuesta del legislador del año 2014 frente a la situación carcelaria en Colombia. Revista Misión Jurídica, 8 (9):199 - 227 DOI: https://doi. org/10.25058/1794600X.105

- Ávila, K. (2017). Homicidios en Venezuela: Principales debates y aproximaciones explicativas. Revista Misión Jurídica 10 (12): 117-140. DOI: https://doi. org/10.25058/1794600X.148

- For Larousse Gran Diccionario. (2020). Gran Diccionario de la Lengua Española. Barcelona: Larousse.

- Higuera Jiménez, D. M. (2016). Tipologías de derechos, ¿Una variante en la tutela 
judicial efectiva?: Un análisis desde la ineficacia de la acción de cumplimiento para los derechos sociales. Revista Vía Iuris, (20): 13-18.

- Higuera, D. M., Hernández, O. \& Cabrera, J. (2018) (Comp.). La población desplazada en Colombia. ¿Hacia un nuevo estado de cosas inconstitucionales? Barranquilla: Sello Editorial Coruniamericana.

- Nino, C. S. (2003). Introducción al Análisis del Derecho. Primera edición 1973. Buenos Aires: Sello editorial Astrea.

- Weber, M. (1999). Economía y sociedad. Esbozo de sociología comprensiva. México: Fondo de Cultura Económica.

- Tébar, V. B. (2004). El modelo de libertad condicional Español. Universidad Autónoma de Barcelona. Tesis Doctoral. Octubre 2004. Recuperado en 16 de marzo de 2020 de https://www.tdx.cat/ handle/10803/5079\#page $=1$.

- Zaffaroni, E. R. (1988). Tratado de Derecho penal. Parte General V. Argentina: Sociedad anónima editora, comercial, industrial y financiera.

\section{Sentencias:}

- Colombia. Corte Constitucional. (17 de septiembre de 2002). Sentencia C-762/02. MP. Rodrigo Escobar Gil. Recuperado en 04 de febrero de 2020 de https:// www.corteconstitucional.gov.co/ relatoria/2002/C-762-02.htm.

- ----- (03 de octubre de 2002). Sentencia C-806/02. MP. Clara Inés Vargas Hernández. Recuperado en 05 de febrero de 2020 de https://www.corteconstitucional.gov.co/ relatoria/2002/C-806-02.htm.

- ----. (26 de octubre de 2005). Sentencia T-1093/05. MP. Clara Inés Vargas Hernández. Recuperado en 08 de febrero de 2020 de https://www.corteconstitucional. gov.co/relatoria/2005/t-1093-05.htm.

- -----. (02 de marzo de 2005). Sentencia C-194/05. MP. Marco Gerardo Monroy
Cabra. Recuperado en 08 de marzo de 2020 de https://www.corteconstitucional.gov. co/relatoria/2005/C-194-05.htm.

- -----. (28 de junio de 2013) Sentencia T-388/13. MP. María Victoria Calle Correa. Recuperado en 09 de febrero de 2020 de https://www.corteconstitucional.gov.co/ relatoria/2013/t-388-13.htm.

- -----. (15 de octubre de 2014). Sentencia C-757/14. MP. Gloria Stella Ortiz Delgado. Recuperado en 25 de marzo de 2020 de https://www.corteconstitucional.gov.co/ relatoria/2014/C-757-14.htm.

- -----. (22 de junio de 2016). Sentencia C-328/16. MP. Gloria Stella Ortiz Delgado. Recuperado en 21 de enero de 2020 de https://www.corteconstitucional.gov.co/ relatoria/2016/c-328-16.htm.

- ----. (17 de octubre de 2017). Sentencia T-640/17. MP. Antonio José Lizarazo Ocampo. Recuperado en 15 de marzo de 2020 de https://www.corteconstitucional. gov.co/relatoria/2017/t-640-17.htm.

- ----. (20 de enero de 2017). Sentencia T-019/17. MP. Gabriel Eduardo Mendoza Martelo. Recuperado en 12 de enero de 2020 de https://www.corteconstitucional. gov.co/relatoria/2017/t-019-17.htm.

- Colombia. Corte Suprema de Justicia, Sala de Casación Penal. (21 de abril de 2016). Proceso No. 85044 M.P. Luis Guillermo Salazar Otero. Recuperado en 16 de marzo de 2020 de https://corte-suprema-justicia. vlex.com.co/vid/691914569.

- ----. Tribunal Superior del Distrito Judicial de Pereira, Sala de Decisión Penal. (13 de diciembre de 2018). Radicado 660016000105201100014 . M.P. Jairo Ernesto Escobar Sanz

\section{Leyes:}

- Congreso de Colombia. Código Penitenciario y Carcelario (Ley 65/1993) Articulo 114. Diario Oficial No. 40.999. ----. Código Penal (Ley 599/2000) Articulo 64 \& 65. Diario 
Oficial No. 44097.

- -----. Código de Procedimiento Penal. (Ley 906/2004). Diario Oficial No. 45.658.

- -----. Código de Infancia y Adolescencia. (Ley 1098/2006). Diario Oficial No. 46.446.

- -----. Ley 1709/2014. Por medio de la cual se reforman algunos artículos de la Ley 65 de 1993, de la Ley 599 de 2000, de la Ley 55 de 1985 y se dictan otras disposiciones.

- -----. Ley 733/2002. Por medio de la cual se dictan medidas tendientes a erradicar los delitos de secuestro, terrorismo y extorsión, y se expiden otras disposiciones. Diario Oficial No 44693.

- ----. Ley 1121/2006. Por la cual se dictan normas para la prevención, detección, investigación y sanción de la financiación del terrorismo y otras disposiciones. Artículo 26. Diario Oficial No 46497.

- ----. Ley 1142/2007. Por medio de la cual se reforman parcialmente las Leyes 906 de 2004, 599 de 2000 y 600 de 2000 y se adoptan medidas para la prevención y represión de la actividad delictiva de especial impacto para la convivencia $y$ seguridad ciudadana. Diario Oficial No 46673.

- ----. Ley 1453/2011. Por medio de la cual se reforma el Código Penal, el Código de Procedimiento Penal, el Código de Infancia y Adolescencia, las reglas sobre extinción de dominio y se dictan otras disposiciones en materia de seguridad. Diario Oficial No 48110.

- ----. Ley 1474/2011. Por la cual se dictan normas orientadas a fortalecer los mecanismos de prevención, investigación y sanción de actos de corrupción y la efectividad del control de la gestión pública.
Artículo 13. Diario Oficial No 48.128.

\section{Revistas INPEC:}

- INPEC. (2014). De entre Muros para la libertad. Volumen 5. Bogotá: Ministerio de Justicia. Recuperado 10 de diciembre de 2019 de https://n9.cl/ksljg

- ----. (2015). De entre Muros para la libertad. Volumen 6. Bogotá: Ministerio de Justicia. Recuperado 10 de diciembre de 2019 de https://n9.cl/sf1b.

- ----. (2017). De entre Muros para la libertad. Volumen 8. Bogotá: Ministerio de Justicia. Recuperado 10 de diciembre de 2019 de https://n9.cl/j9950.

- ----. (2017b). Informes y Boletines Estadísticos. Recuperado 10 de diciembre de 2019 de https://n9.cl/lqnt

- ----. (2018). De entre Muros para la libertad. Volumen 9. Bogotá: Ministerio de Justicia. Recuperado 10 de diciembre de 2019 de https://n9.cl/15h28.

- ----. (2019a). Informe estadístico población reclusa a cargo del INPEC, oficina asesora de Planeación. Recuperado 12 de diciembre de 2019 de https://n9.cl/jggub.

- ----. (2019b). Informes y Boletines Estadísticos. Recuperado 10 de diciembre de 2019 de https://n9.cl/jw6t.

- ----. (2020). Informe estadístico población privada de la libertad. Recuperado 10 de marzo de 2020 de https://n9.cl/juos5.

- Web Revista Semana. (2014). 9000 Presos salen de cárceles por hacinamiento. Revista Semana. Recuperado 005 de enero de 2020 de http://www.revistas.unal. edu.co/index.php/psicologia/article/ view/27899/43273. 